\title{
Article \\ Multi-Stimulus Responsive Multilayer Coating for Treatment of Device-Associated Infections
}

\author{
Wenlong Li ${ }^{1,+}\left(\mathbb{D}\right.$, Guanping Hua ${ }^{1,+}$, Jingfeng Cai ${ }^{1}$, Yaming Zhou ${ }^{1}$, Xi Zhou ${ }^{1}$, Miao Wang ${ }^{1, *}$, Xiumin Wang $^{2}$, \\ Baoqing $\mathrm{Fu}^{3, *}$ and Lei Ren ${ }^{1,4, *}$
}

check for

updates

Citation: Li, W.; Hua, G.; Cai, J.; Zhou, Y.; Zhou, X.; Wang, M.; Wang, X.; Fu, B.; Ren, L. Multi-Stimulus Responsive Multilayer Coating for Treatment of Device-Associated Infections. J. Funct. Biomater. 2022, 13, 24. https://doi.org/10.3390/ jfb13010024

Academic Editors: James Kit-hon Tsoi, Huiliang Cao and Yuqin Qiao

Received: 30 January 2022

Accepted: 25 February 2022

Published: 28 February 2022

Publisher's Note: MDPI stays neutral with regard to jurisdictional claims in published maps and institutional affiliations.

Copyright: (c) 2022 by the authors. Licensee MDPI, Basel, Switzerland. This article is an open access article distributed under the terms and conditions of the Creative Commons Attribution (CC BY) license (https:// creativecommons.org/licenses/by/ $4.0 /)$.
1 Higher Educational Key Laboratory for Biomedical Engineering of Fujian Province, Research Center of Biomedical Engineering of Xiamen, Department of Biomaterials, College of Materials, Xiamen University, 422 Siming Nan Road, Xiamen 361005, China; 20720190153834@stu.xmu.edu.cn (W.L.); hgpailber@163.com (G.H.); 20720201150033@stu.xmu.edu.cn (J.C.); blue_zzyymm@163.com (Y.Z.); xizhou@xmu.edu.cn (X.Z.)

2 School of Pharmaceutical Sciences, Xiamen University, Xiamen 361102, China; wangxm@xmu.edu.cn

3 Department of Laboratory Medicine, Xiang'an Hospital of Xiamen University, School of Medicine, Xiamen University, Xiamen 361102, China

4 State Key Laboratory of Physical Chemistry of Solid Surfaces, College of Chemistry and Chemical Engineering, Xiamen University, Xiamen 361005, China

* Correspondence: miaowang@xmu.edu.cn (M.W.); fbq@sina.com (B.F.); renlei@xmu.edu.cn (L.R.)

+ These authors contributed equally to this work.

\begin{abstract}
Antibacterial coating with antibiotics is highly effective in avoiding device-associated infections (DAIs) which is an unsolved healthcare problem that causes significant morbidity and mortality rates. However, bacterial drug resistance caused by uncontrolled release of antibiotics seriously restricts clinical efficacy of antibacterial coating. Hence, a local and controlled-release system which can release antibiotics in response to bacterial infected signals is necessary in antibacterial coating. Herein, a multi-stimulus responsive multilayer antibacterial coating was prepared through layer-by-layer (LbL) self-assembly of montmorillonite (MMT), chlorhexidine acetate (CHA) and Poly(protocatechuic acid-polyethylene glycol 1000-bis(phenylboronic acid carbamoyl) cystamine) (PPPB). The coating can be covered on various substrates such as cellulose acetate membrane, polyacrylonitrile membrane, polyvinyl chloride membrane, and polyurethane membrane, proving it is a versatile coating. Under the stimulation of acids, glucose or dithiothreitol, this coating was able to achieve controlled release of $\mathrm{CHA}$ and kill more than $99 \%$ of Staphylococcus aureus and Escherichia coli $\left(4 \times 10^{8} \mathrm{CFU} / \mathrm{mL}\right)$ within $4 \mathrm{~h}$. In the mouse infection model, $\mathrm{CHA}$ releasing of the coating was triggered by infected microenvironment to completely kill bacteria, achieving wounds healing within 14 days.
\end{abstract}

Keywords: device-associated infections; multi-stimulus responsiveness; antibacterial coating; wound healing

\section{Introduction}

Nosocomial infection is acquired in healthcare facilities [1]. More than 50\% nosocomial infections are related to medical devices [2]. Even with aseptic techniques, microbial communities from the patient's surface or external environment can be attached to medical devices leading to device-associated infections (DAIs) which is a major health care problem that has not been solved [3]. For instance, the substantial mortality caused by catheterassociated infection have reached 25\% [4,5]. A study from the World Health Organization demonstrated that patients in the intensive care unit (ICU) are at a significantly higher risk of acquiring DAIs. About $30 \%$ of patients have experienced at least one DAIs with significant associated morbidity and mortality [6].

To prevent the occurrence of DAIs, a promising strategy is to modify the antibiotics on the devices surface [7]. Chlorhexidine acetate (CHA), a kind of common broad-spectrum antibiotic, carries a large number of positive groups that can bind to the anionic sites on 
the bacteria membrane [8]. This binding can disrupt bacteria membrane potential and cause varying degrees of membrane damage [9]. Therefore, it is difficult for bacteria to develop resistance to $\mathrm{CHA}$ [10]. Given the above advantages, $\mathrm{CHA}$ is often used as an antibacterial component of the antibacterial coating. For instance, Usha et al. modified $\mathrm{CHA}$ on the surface of fabrics and achieved the destruction of bacteria (almost 100\%) within $24 \mathrm{~h}$ [11]. However, these kinds of antibacterial coatings have obvious defects. While killing bacteria, abundant surface positive charges will cause a large number of bacterial fragments to accumulate, and the antibacterial ability of the coatings will soon fail [12]. At the same time, excessive release of antibiotics also contributes to the development of bacterial resistance [13]. In order to solve the above problems, nano-lamellar MMT, as a material with large specific surface area, good absorbability, good biocompatibility, and drug carrying capability, was used to load CHA to complete slow drug release [14]. MMT can load positively charged substances such as CHA between the lamellar layers through cation exchange effect [15]. However, this drug delivery mode can only play a role of slow release, but cannot achieve the effect of on-demand release and sustained maintenance of antibacterial properties. Therefore, how to maintain the antibacterial ability of cationic antibacterial coating on the medical device surface and significantly reduce the toxicity and bacterial resistance is a major bottleneck in current research [16].

In recent years, stimulus-responsive antibacterial coatings have attracted great attention because of the reduction of the excessive release of antibiotics. This antibacterial coating can be used for topical drug delivery by responding to the bacterial infection microenvironment (e.g., weak acid environment $(\mathrm{pH}<5)$, high peptidoglycan content, and high glutathione content) [17], which will inhibit the development of antibiotics resistance and achieve the long-term antibacterial effect. Most of the previous work on stimuli-responsive antibacterial coatings has focused on responding to a single stimulus (e.g., pH, electric field, light, temperature or bioactive molecules [18-22]). Although such single stimulusresponsive antibacterial coatings have been researched deeply in the treatment of DAIs, it is clear that antibacterial coatings with multi-stimulus responsive ability would be more advantageous and widely applied. Because multiple stimulus occurs simultaneously in a real biological and physical environment [7]. For example, Yang Zhou et al. [23] constructed a surface coating with a multi-stimulus response on a silicon substrate containing thermally responsive components poly( $N$-isopropylacrylamide) (PNIPAAm) and phenylboric acid. The coating can respond to changes of $\mathrm{pH}$, sugar and temperature in the biological environment to release drugs and kill bacteria. Therefore, constructing multi-stimulus-responsive antibacterial coatings that are sensitive to the bacterial infection environment may serve as a good strategy for the treatment of DAIs.

However, most coatings are highly selective to the substrate and are limited to the variety of substrate materials [24]. Therefore, it is necessary to develop a kind of coating that can modify the surface of various substrate. In this process, we need to integrate antibacterial agents and responsive drug delivery systems into the coating material. However, it is not easy to load antibiotics into releasing systems because the weak binding between the matrix and small molecules [25], which would result in bacterial antibiotic resistance [26]. Layer-by-layer (LbL) technology provides a solution to this problem. LbL technology originally refers to a technique of forming self-assembled multilayers on charged substrates by alternating deposition of polyelectrolytes, which was first studied and proposed by $\mathrm{R}$. K. Iler [27]. Since the 1990s, LbL technology has developed rapidly. LbL technology can be widely used in various forms (e.g., spraying or immersion) for surface modification of various materials (e.g., planar or particulate substrates) [28]. It has been proved that LbL assembly could provide a controlled carrier system in respect of releasing antibiotics [29]. LbL self-assembly technology has the ability to fully absorb and retain the biological activity of the drug, which is used to construct a good responsive drug releasing mechanism on the surface of the medical devices.

In this paper, a multi-stimulus responsive multilayer antibacterial coating (MMT$\mathrm{PPPB}-\mathrm{CHA})_{\mathrm{n}}$ was prepared by the electrostatic adsorption between the inorganic nano- 
lamellar MMT, cationic antibacterial agent CHA and PPPB (Figure 1). We studied the drug loading capacity, drug release capacity, and antibacterial activity of (MMT-PPPB-CHA) coating to prove that the coating can be a versatile material used to modify a variety of substrate, and the coating has good drug loading ability and responsive drug release ability. In addition, a mouse epidermal infection model was established to study the in vivo antibacterial activity of (MMT-PPPB-CHA) $)_{\mathrm{n}}$ coating. This coating can respond to the microenvironment of bacterial infection (such as weak acid environment $(\mathrm{pH}<5)$, high peptidoglycan content, and high glutathione content) to release cationic CHA, providing a new strategy for solving DAIs.

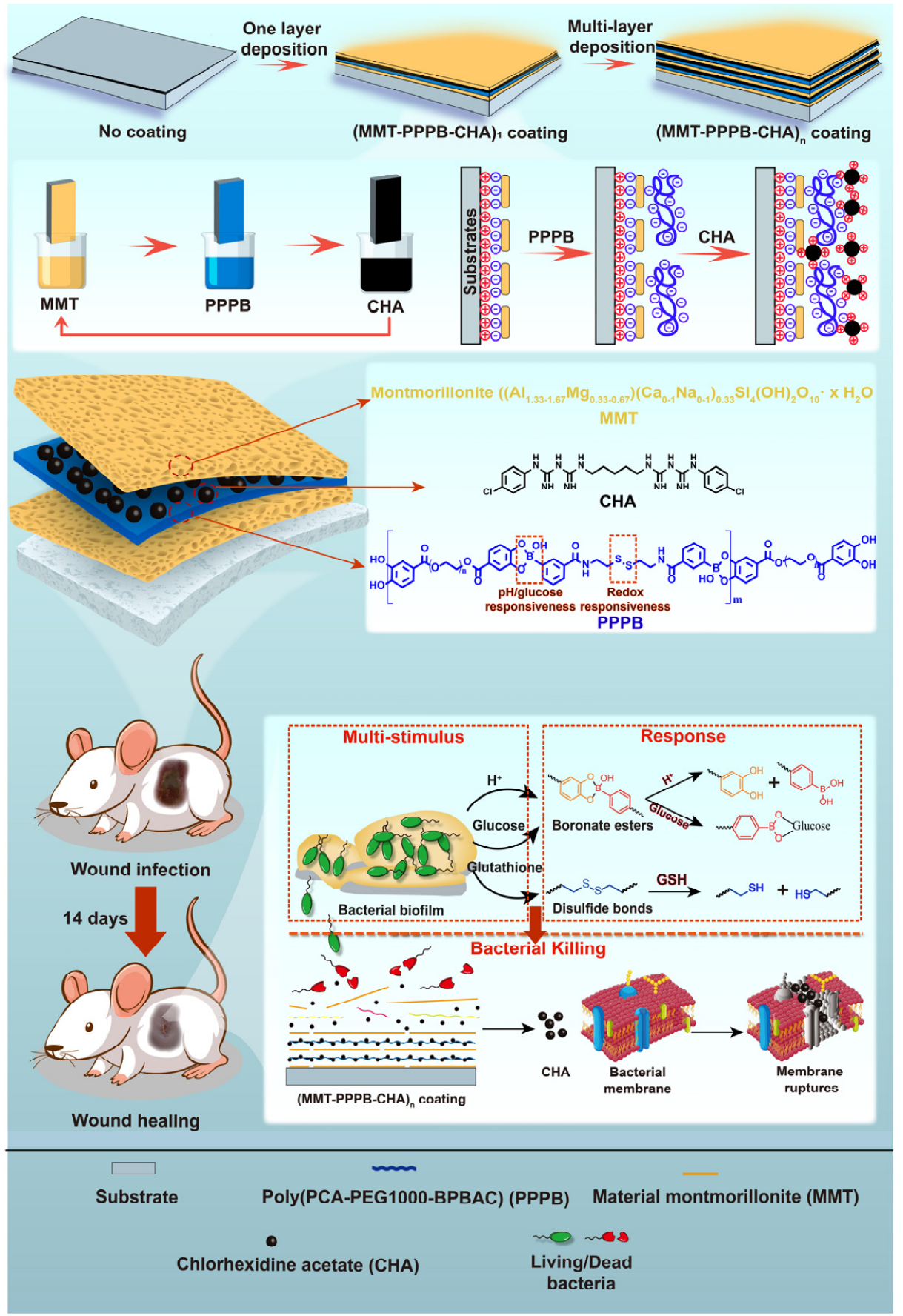

Figure 1. Schematic illustration of the multi-stimulus responsive multilayer antibacterial coating (MMT-PPPB-CHA $)_{n}$. 


\section{Materials and Methods}

\subsection{Materials and Instrumentation}

Ethanol absolute (AR Grade, $\geq 99.7 \%$ ) and chloroform (AR Grade, $\geq 99.0 \%$ ) were purchased from Sinopharm Chemical Reagent Shanghai Co., Ltd. (Shanghai, China). Acetic acid (AR Grade, $\geq 99.5 \%$ ), phosphate buffer saline (PBS buffer), and dimethyl sulfoxide (DMSO, molecular biology grade, $\geq 99.7 \%$ ), 1-(3-Dimethylaminopropyl)-3-ethylcarbodiimide hydro (EDC, $\geq 95.0 \%$, C600433-0025), glucose ( $\geq 99.8 \%$, A100188-0005) were purchased from Sangon Biotechnology Co., Ltd. (Shanghai, China). E. coli (ATCC 43888) and S. aureus (ATCC BAA-1721) were purchased from China Center of Industrial Culture Collection, CICC. Chlorhexidine acetate (CHA, $\geq 99.0 \%, \mathrm{C107054)}$ ), dithiothreitol (DTT, $\geq 99.0 \%$, D104859), cysteamine dihydrochloride (CYS, $\geq 97.0 \%, C 153647)$, protocatechuic acid (PCA, $\geq 97.0 \%$, S30117), polyethylene glycol 1000 (PEG1000, AR Grade, 12803702) were purchased from Aladdin (Co. Ltd. Shanghai, China). MMT k-10 (M813515), 3-carboxyphenyl boric acid (CPBA, $\geq 99.0 \%$, C804442), 4-Dimethylaminopyridine (DMAP, $\geq 97.0 \%$, D807273), NHydroxysuccinimide (NHS, $\geq 97.0 \%$, N811124) Ethylene imine polymer (PEI, $\geq 99.0 \%$, E808878), Deuterium oxide $\left(\mathrm{D}_{2} \mathrm{O}, \geq 99.9 \%\right.$, D807644), Methanol-d4 $\left(\mathrm{CD}_{3} \mathrm{OD}, \geq 99.9 \%\right.$, M812876), DMSO-d6 ( $\geq$ 99.9\%, D806935) were purchased from Macklin Biochemical Co., Ltd. (Shanghai, China).

\subsection{Synthesis of $P P P B$}

Firstly, $1.65 \mathrm{~g} \mathrm{CPBA}(10.0 \mathrm{mmol}), 1.53 \mathrm{~g}$ EDC ( $8.0 \mathrm{mmol})$, and $1.40 \mathrm{~g}$ NHS (12.2 mmol) were accurately weighed and dissolved in $100 \mathrm{~mL}$ PBS buffer ( $\mathrm{pH}$ 6.86). After incubation for $2 \mathrm{~h}$ under full stirring at room temperature, $0.90 \mathrm{~g} \mathrm{CYS}(4.0 \mathrm{mmol})$ was added, and then the reaction mixture was continuously stirred at room temperature for $12 \mathrm{~h}$. The precipitate produced by the reaction was filtered, washed several times with PBS and ultrapure water, and then centrifuged twice at $6000 \mathrm{rpm}$. The product was vacuum dried at $60{ }^{\circ} \mathrm{C}$, and finally recrystallized and purified with methanol to obtain white powder BPBAC.

Secondly, $1.54 \mathrm{~g}$ PCA and $2.50 \mathrm{~g}$ PEG1000 were accurately weighed and dissolved in $20.0 \mathrm{~mL}$ DMSO solution. $1.92 \mathrm{~g}$ EDC and $305 \mathrm{mg}$ DMAP were added under stirring conditions, and the reaction was carried out at room temperature for $48 \mathrm{~h}$. After the reaction, the precipitate was removed by filtration, and the filtrate was dialyzed by dialysis bag with molecular weight cut-off 1000 . The dialysate was firstly dialyzed by DMSO for $12 \mathrm{~h}$, and then by ultrapure water for $36 \mathrm{~h}$. The dialysate was changed every $6 \mathrm{~h}$ during dialysis. After dialysis, the product was precipitated into dark yellow solid and dried in vacuum at $30{ }^{\circ} \mathrm{C}$ to obtain PCA-PEG1000.

Finally, bis(phenylboronic acid carbamoyl) cystamine (BPBAC) was dissolved in a small amount of methanol solution, then BPBAC methanol solution and PCA-PEG1000 were fully dissolved in $20.0 \mathrm{~mL} \mathrm{NaOH}$ aqueous solution $(\mathrm{pH} 10.0)$, and stirred at $300 \mathrm{rpm}$ for $12 \mathrm{~h}$ at room temperature. At the end of the reaction, dialysis bags with molecular weight cut-off 1000 were used in $\mathrm{NaOH}$ solution with $\mathrm{pH} 10.0$ for $48 \mathrm{~h}$, and dialysate was changed every $8 \mathrm{~h}$. Finally, the solution was freeze-dried to obtain a dark yellow colloidal substance, namely PPPB.

\subsection{Synthesis of $(M M T-P P P B-C H A)_{n}$ Coating}

Nanosheet MMT was first prepared. $0.8 \mathrm{~g}$ MMT was dissolved in $20.0 \mathrm{~mL}$ ultrapure water and $20.0 \mathrm{~mL}$ methanol, respectively. After sealing and stirring at room temperature for 1 week, $40.0 \mathrm{mg} / \mathrm{mL}$ nanosheet MMT aqueous dispersion and $40.0 \mathrm{mg} / \mathrm{mL}$ nanosheet MMT methanol dispersion were prepared for standby.

The substrate was immersed in PEI solution $(0.5 \mathrm{mg} / \mathrm{mL})$ for $5 \mathrm{~min}$ to form a precursor layer. Then, the composite coating (MMT-PPPB-CHA $)_{n}$ was prepared according to the following steps: (1) The substrate was soaked in $1.0 \mathrm{mg} / \mathrm{mL}$ MMT dispersion for $30 \mathrm{~s}$ and then dried naturally. (2) Natural drying after immersion in $1.0 \mathrm{mg} / \mathrm{mL}$ PPPB solution for $30 \mathrm{~s}$. (3) Natural drying after soaking in $2.0 \mathrm{mg} / \mathrm{mL}$ CHA solution for $15 \mathrm{~s}$. In this preparation process, the substrate surface is covered with MMT layer, then PPPB layer, and 
finally CHA layer, forming a layer (MMT-PPPB-CHA) coating. Repeat the above steps " $\mathrm{n}$ " times, (MMT-PPPB-CHA) $n$ coating was prepared on the surface of substrates. The substrate surface coatings only modified with MMT and MMT-CHA were prepared by the same method, denoted as (MMT) $)_{n}$ and (MMT-CHA $)_{n}$, respectively, as the control groups. In order to ensure the accuracy and objectivity of performance characterization, the prepared coating was washed with pure water and PBS buffer ( $\mathrm{pH}$ 7.4) for three times before the test, in order to remove the excess CHA, PPPB and MMT that did not form the coating during the preparation process.

\subsection{Characterization of Polymers $P P P B$}

The FT-IR spectra of BPBAC, PCA-PEG1000, and PPPB were recorded on a Nicolet 6700 FT-IR spectrometer (Thermo Scientific) in the $4000-600 \mathrm{~cm}^{-1}$ range. The ${ }^{1} \mathrm{H}$ nuclear magnetic resonance $\left({ }^{1} \mathrm{H}\right.$ NMR) (AVANCE III $400 \mathrm{MHz}$, Bruker, Karlsruhe, Germany) of BPBAC, PCA-PEG1000, and PPPB was recorded at $25^{\circ} \mathrm{C}$ using $\mathrm{CD}_{3} \mathrm{OD}$, DMSO-d6, and $\mathrm{D}_{2} \mathrm{O}$ as solvent separately. The Ultraviolet-visible (UV-vis) absorption spectra of PPPB products with the three stimuli were determined by UV spectro-photometer (UV-2550, Shimadzu, Tokyo, Japan).

\subsection{Characterization of (MMT-PPPB-CHA) ${ }_{n}$ Coating}

The morphology of (MMT-PPPB-CHA $)_{n}$ coating was characterized by a field emission scanning electron microscope (SEM, SU-70, Hitachi Nake high-tech enterprise, Tokyo, Japan) at an acceleration voltage of $5 \mathrm{kV}$. X-ray diffraction (XRD) was performed with the Axs D8-A25 advance (Bruker, Karlsruhe, Germany). The Fourier transform infrared (FTIR) spectra assay was performed using a Nicolet iS10 (Thermo Scientific, Waltham, MA, USA) with the $\mathrm{KBr}$ pellet technique. UV-vis absorption spectra were acquired with the UV spectrophotometer (UV-2550, Shimadzu, Karlsruhe, Germany, Japan). MMT, PPPB, and CHA were prepared into $0.5 \mathrm{mg} / \mathrm{mL}$ solution. (MMT-CHA) ${ }_{3}$ and (MMT-PPPB-CHA) $)_{3}$ coatings were scraped off the substrate and dispersed in water to form a suspension $(0.5 \mathrm{mg} / \mathrm{mL})$. The Zeta potential of samples was measured by Malvern Mastersizer 2000 particle size and potential analyzer (Mastersizer2000/MAL1012737, Spectris, Shanghai, China). First of all, the test mode was set as potential test in Zetasizer Software (test temperature: $25^{\circ} \mathrm{C}$, number of repeated tests: 3 times, and potential sample pool model: Dts1070). Then, the solution or suspension was fully shaken and injected at the calibration line of the sample pool. Then, the sample pool was put into the analyzer. Finally, the potential values measured in the three experiments were averaged as the final sample Zeta potential. The water contact angle of samples was measured by a dynamic water contact angle measuring instrument (OCA20, Dataphysics, Germany, Esslingen, Germany).

\subsection{The Standard Curve of $\mathrm{CHA}$}

The concentration of CHA solution prepared was $0.1 \mathrm{mg} / \mathrm{mL}, 0.05 \mathrm{mg} / \mathrm{mL}, 0.025 \mathrm{mg} / \mathrm{mL}$, $0.01 \mathrm{mg} / \mathrm{mL}, 0.005 \mathrm{mg} / \mathrm{mL}$ and $0.0025 \mathrm{mg} / \mathrm{mL}$, respectively. The absorbance of CHA at $252 \mathrm{~nm}$ was measured by a UV-VIS spectrophotometer (UV-2550, Shimadzu, China) with three times to take the average value. Then the standard curve of $\mathrm{CHA}$ concentration and absorbance was drawn.

\subsection{CHA Loading Capacity of (MMT-PPPB-CHA ${ }_{n}$ Coating}

Five groups of (MMT-PPPB-CHA) coatings $(n=2,4,8,12$, and 16) were constructed on the CA films with an area of $2 \mathrm{~cm}^{2}$ according to the above steps. $5.0 \mathrm{~mL}$ CHA solution with the concentration of $5.0 \mathrm{mg} / \mathrm{mL}$. To facilitate the calculation, $0.5 \mathrm{~mL} \mathrm{CHA}(5.0 \mathrm{mg} / \mathrm{mL})$ was used in preparation. After the preparation, we collected the remaining CHA solution 
and tested the absorbance of CHA at $252 \mathrm{~nm}$. The relationship between drug loading $\left(\mu \mathrm{g} / \mathrm{cm}^{2}\right)$ and layers number was further calculated. The calculation formula is:

$$
\text { CHA content per unit area }\left(\mu \mathrm{g} / \mathrm{cm}^{2}\right)=\frac{\text { Total dose }(\mu \mathrm{g})-\text { Remaining dose }(\mu \mathrm{g})}{\text { Total area }\left(\mathrm{cm}^{2}\right)}
$$

\subsection{Sustained Drug-Releasing Capacity of (MMT-PPPB-CHA) ${ }_{3}$ Coating}

The coating $\left(1 \times 2 \mathrm{~cm}^{2}\right)$ was put into $5.0 \mathrm{~mL}$ PBS buffer. $0.5 \mathrm{~mL}$ of the release medium was taken out successively at $1,2,4,12,24,48$, and $72 \mathrm{~h}$, and the same amount of PBS buffer was immediately replaced after taking. The absorbance of CHA was measured at $252 \mathrm{~nm}$ by an UV-VIS spectrophotometer (UV-2550, Shimadzu, China), and the CHA release kinetics curves of the different coating were obtained within $72 \mathrm{~h}$.

\subsection{Multi-Stimulus Responsive Ability of (MMT-PPPB-CHA) ${ }_{3}$ Coating}

The (MMT-PPPB-CHA) $)_{3}$ coating $\left(1 \times 2 \mathrm{~cm}^{2}\right)$ was placed in $5.0 \mathrm{~mL}$ release media with different $\mathrm{pH}$ values $(5.5,6.0,7.0$, and 8.0$)$, different concentrations of glucose solutions $(0,0.5$, and $1.0 \mathrm{mg} / \mathrm{mL})$ and different concentrations of DTT solutions $(0,0.5$, and $1.0 \mathrm{mg} / \mathrm{mL})$, respectively. $0.5 \mathrm{~mL}$ release medium was taken out successively at $1,2,4,12,24,48$, and $72 \mathrm{~h}$, and an equal amount of release medium with corresponding $\mathrm{pH}$ value was immediately replaced after taking. The absorbance of the CHA was measured at $252 \mathrm{~nm}$ by an UV-VIS spectrophotometer (UV-2550, Shimadzu, China), and the release kinetics curve of CHA was obtained according to the standard curve.

To further explore the synergistic drug release behavior of (MMT-PPPB-CHA) 3 coating, orthogonal test $\mathrm{L}_{9}\left(3^{4}\right)$ (three factors and three levels) was used to study the synergistic drug release effect of (MMT-PPPB-CHA $)_{3}$ coating under the different conditions. The orthogonal test results were analyzed as shown in Table 1.

Table 1. The result analysis of $\mathrm{L}_{9}\left(3^{4}\right)$ orthogonal test.

\begin{tabular}{|c|c|c|c|c|}
\hline \multirow{2}{*}{ Groups } & \multicolumn{3}{|c|}{ Factors } & \multirow{2}{*}{ CHA Release Rate (\%) } \\
\hline & $\mathrm{pH}$ & Glucose $(\mathrm{mg} / \mathrm{mL})$ & DTT (mg/mL) & \\
\hline $\mathrm{a}$ & 6.0 & 0 & 0 & $56.0 \pm 3.2$ \\
\hline $\mathrm{b}$ & 6.0 & 0.5 & 0.5 & $60.1 \pm 2.0$ \\
\hline C & 6.0 & 1.0 & 1.0 & $70.1 \pm 1.3$ \\
\hline $\mathrm{d}$ & 7.0 & 0 & 0.5 & $56.7 \pm 1.7$ \\
\hline $\mathrm{e}$ & 7.0 & 0.5 & 1.0 & $62.0 \pm 2.3$ \\
\hline $\mathrm{f}$ & 7.0 & 1.0 & 0 & $53.9 \pm 1.1$ \\
\hline $\mathrm{g}$ & 8.0 & 0 & 1.0 & $43.3 \pm 1.6$ \\
\hline $\mathrm{h}$ & 8.0 & 0.5 & 0 & $34.3 \pm 1.8$ \\
\hline $\mathrm{i}$ & 8.0 & 1.0 & 0.5 & $50.7 \pm 2.8$ \\
\hline K1 & 186.2 & 156.0 & 144.2 & \\
\hline $\mathrm{K} 2$ & 172.6 & 156.4 & 167.8 & \\
\hline K3 & 128.3 & 174.7 & 175.4 & \\
\hline $\mathrm{k} 1$ & 62.1 & 52.0 & 48.1 & \\
\hline $\mathrm{k} 2$ & 57.5 & 52.1 & 55.9 & \\
\hline k3 & 42.8 & 58.2 & 58.5 & \\
\hline $\mathrm{R}$ & 19.3 & 6.2 & 10.4 & \\
\hline
\end{tabular}

\subsection{Preparation of Bacteria Suspensions}

E. coli (ATCC 43888) and S. aureus (ATCC BAA-1721) were cultured in $10 \mathrm{~mL}$ LB broth at $37^{\circ} \mathrm{C}$ for $6 \mathrm{~h}$. After culturing, the bacterial sediments were resuspended and washed with normal saline $(0.9 \%$, pH 7.4). Finally, the bacteria suspension was diluted to an optical density of 0.1 at $600 \mathrm{~nm}(\mathrm{OD} 600=0.1)$ 


\subsection{In Vitro Antibacterial Activity of (MMT-PPPB-CHA) ${ }_{3}$ Coating}

The coated or uncoated substrate was co-cultured with bacteria suspension at different $\mathrm{pH}$ values (6.0, 7.0 and 8.0), different concentrations of DTT solutions $(0,0.5$, and $1.0 \mathrm{mg} / \mathrm{mL}$ ), and glucose solutions $(0,0.5$, and $1.0 \mathrm{mg} / \mathrm{mL})$ for $2 \mathrm{~h}$, respectively. Then, $100 \mu \mathrm{L}$ of the bacteria suspension was taken out and inoculated on AGAR medium. After $16 \mathrm{~h}$ of static culture, the number of colonies was counted and digital photos of culture plates were taken.

Fluorescein isothiocyanate (FITC) was dissolved in DMSO to prepare the $1 \mathrm{mM}$ FITC solution. Live bacteria were labeled with $100 \mu \mathrm{L}$ FITC solution and incubated with the coated or uncoated substrate at different $\mathrm{pH}$ values (6.0, 7.0 and 8.0), different concentrations of DTT solutions $(0,0.5$, and $1.0 \mathrm{mg} / \mathrm{mL})$, and glucose solutions $(0,0.5$, and $1.0 \mathrm{mg} / \mathrm{mL}$ ) for $2 \mathrm{~h}$, respectively. The bacteria suspension was dropped into the surface dish specially used for laser confocal microscopy, and the survival of the bacteria was further observed under a laser confocal microscopy (SP8-STED 3X, Leica, German).

The bacteria were fixed with $2 \%$ glutaraldehyde aqueous solution, and then the gradient dehydration was carried out with $10 \%, 20 \%, 30 \%, 40 \%, 50 \%, 70 \%, 90 \%, 100 \%$ ethanol aqueous solution successively. The growth and adhesion of bacteria on the surface of the coating material were observed under a SEM (SU-70, Hitachi Nake High-Tech Enterprise, Tokyo, Japan) after dehydration.

\subsection{Long-Term Antibacterial Performance of (MMT-PPPB-CHA) ${ }_{3}$ Coating}

Sterilized CHA, (MMT-CHA) ${ }_{3}$ and (MMT-PPPB-CHA) ${ }_{3}$ coated and uncoated substrates were placed in $5.0 \mathrm{~mL}$ bacteria suspension, respectively. Take $100 \mu \mathrm{L}$ of bacteria solution from each group every $4 \mathrm{~h}$ and inoculate them into the AGAR medium for colony counting. At the same time, the bacteria liquid of each group was discarded, cleaned with sterile normal saline, and $5.0 \mathrm{~mL}$ of bacteria suspension was added again to continue co-culture. Repeat the preceding steps six times.

\subsection{In Vivo Antibacterial Activity and Full-Thickness Skin Defect Healing}

Female BALB/c mice ( 8 weeks, 15-20 g) were obtained from Laboratory Animal Center of Xiamen University and divided into five groups with three mice in each group: (1) normal saline (control); (2) uncoated substrate; (3) CHA coated substrate; (4) (MMTCHA) ${ }_{3}$ coated substrate; (5) (MMT-PPPB-CHA) ${ }_{3}$ coated substrate.

$10 \mu \mathrm{L}$ of S. aureus and E. coli solution with a concentration of $1.0 \times 10^{6} \mathrm{CFU} / \mathrm{mL}$ was subcutaneously injected into the back of mice. $48 \mathrm{~h}$ later, obvious suppurative infection symptoms could be observed at the bacteria inoculated site on the back of mice. The suppurative infection site was cut open with a sterilized scalpel to form an open resection wound with a diameter of about $6 \mathrm{~mm}$. Corresponding materials were affixed to the wound of each mouse and fixed with medical tape. The materials were removed $24 \mathrm{~h}$ later.

All mice were weighed every $24 \mathrm{~h}$, and the wound healing of the subcutaneous infected site was observed and photographed at certain intervals. ImageJ was used to measure the change of wound area at different periods to calculate the wound healing rate [30], which was calculated as follows:

$$
\text { Wound healing rate }(\%)=\left(1-\frac{\text { wound area on day } n}{\text { wound area on day } 0}\right) \times 100 \%
$$

Finally, the mice were killed, and the bacterial concentration of the infected tissue was observed on the AGAR plate. This in vivo experiment has been approved by the Institutional Animal Care and Use Committee of Xiamen University. Approval date: 26 February 2018; Approval code: XMULAC20180003.

\subsection{Statistical Analysis}

Data are expressed as mean \pm S.D. At least three independent experiments were performed for in vitro experiments. Statistical analysis was carried out using SPSS version 
18.0, Origin 2021 and GraphPad Prism 7.00. Data were analyzed by two-sided student t-tests for comparison of two groups and one-way ANOVA for multiple groups.

\section{Results and Discussion}

\subsection{Synthesis of the Multi-Stimulus Responsive Polymer PРPB}

We firstly synthesized a multi-stimulus responsive polymer PPPB based on phenylborate ester bond and disulfide bond (Figure 2a) to construct a multi-stimulus responsive antibacterial coating. PPPB was synthesized through dynamic covalent reactions between BPBAC (Figure S1) and PCA-PEG1000 (Figure S2) under alkaline conditions (pH 10.0). The structure of PPPB was identified based on IR and ${ }^{1} \mathrm{H}$ NMR spectrum. The position and peak area ratio (1:1) of the characteristic peaks $(\delta 2.9 \mathrm{ppm}$ and $\delta 3.6 \mathrm{ppm})$ indicated that PPPB possessed the characteristic structure of both BPBAC and PCA-PEG1000 (Figure 2b). Moreover, IR spectrum of PPPB also showed the characteristic peaks of BPBAC and PCAPEG1000 at $2919 \mathrm{~cm}^{-1}(\mathrm{C}-\mathrm{H})$ and $1641 \mathrm{~cm}^{-1}(\mathrm{C}=\mathrm{O})$ (Figure 2c). More importantly, the disappearance of characteristic peaks at $1347 \mathrm{~cm}^{-1}$ indicated the phenylboronic acid was transformed to boronate ester, further confirming the successful synthesis of PPPB.

a
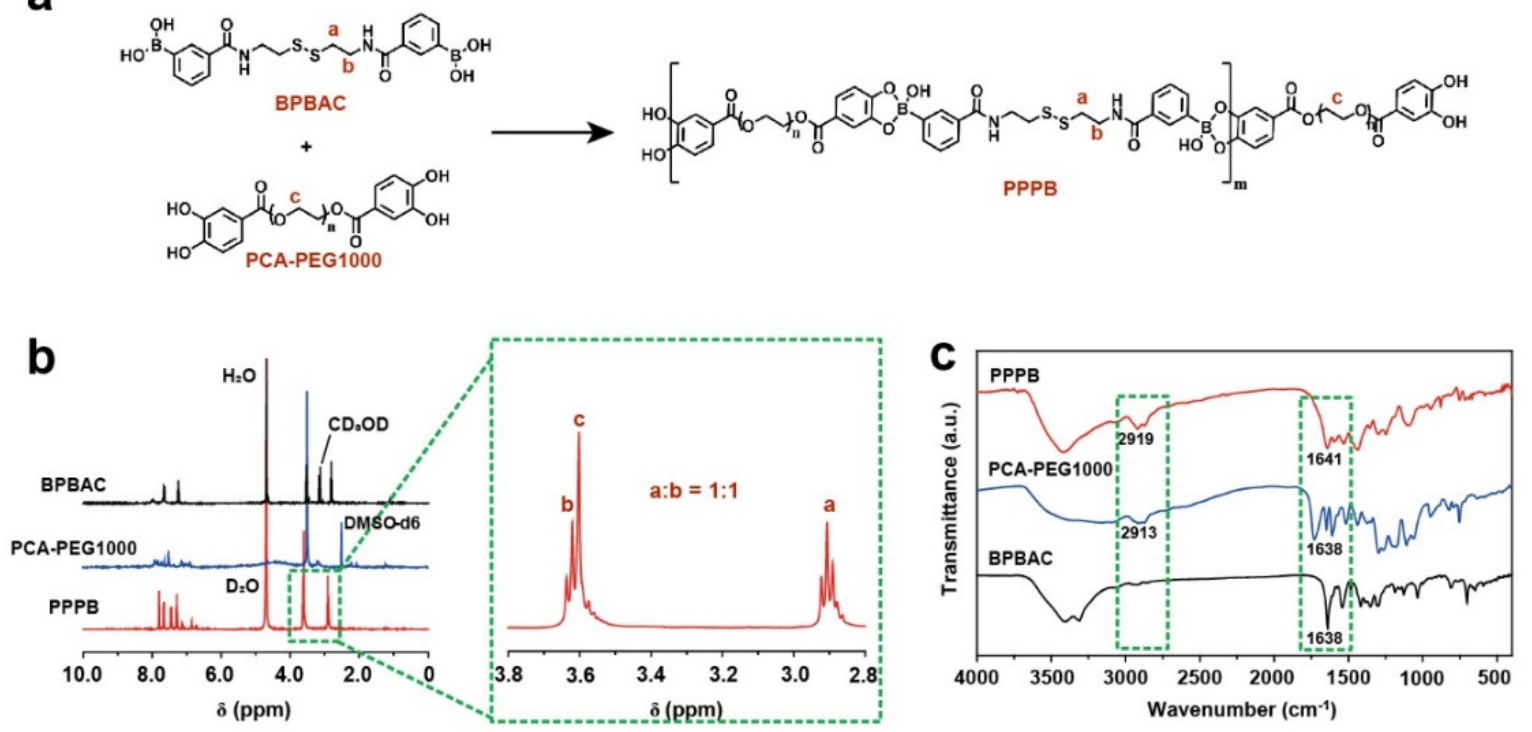

Figure 2. (a) Chemical structural formula of polymer PPPB; (b) ${ }^{1} \mathrm{H}-\mathrm{NMR}$ spectrums of PPPB, PCAPEG1000 and BPBAC; (c) FT-IR absorbance spectrums of PPPB, PCA-PEG1000, and BPBAC.

Due to the presence of boronate ester and disulfide bonds, polymer PPPB should exhibit pH-, glucose-, and redox-responsive features theoretically (Figure S3a). Therefore, the multi-stimulus responsive degradation behavior of PPPB was explained by UV-absorption, IR and ${ }^{1} \mathrm{H}$ NMR spectrum. As shown in Figure S3b, PPPB displayed a distinct corresponding UV peak with an absorption maximum at $300 \mathrm{~nm}$. However, the intensity of the peak decreased with the addition of PBS buffer ( $\mathrm{pH}$ 6.0), glucose aqueous solution $(0.5 \mathrm{mg} / \mathrm{mL})$ and DTT aqueous solution $(0.5 \mathrm{mg} / \mathrm{mL})$, indicating that the disulfide bond content in the product is reduced. In order to further analyze the stimulus responsiveness of PPPB, we purified the products by dialysis (molecular weight cut-off: $1000 \mathrm{Da}$ ), which means that the product obtained by dialysis should be the part containing PEG-1000 fragment. Disulfide bonds in polymer PPPB break when DTT stimulus responsiveness occurs. According to Figure 3, the intercepted part of the broken PPPB should contain part of the structure of BPBAC molecule, which means the existence of the characteristic peak of $-\mathrm{S}_{-} \mathrm{CH}_{2}-(\delta 2.9 \mathrm{ppm})$ in the ${ }^{1} \mathrm{H}-\mathrm{NMR}$ spectrum. On the contrary, the disappearance of the characteristic peak of-S- $\mathrm{CH}_{2}-(\delta 2.9 \mathrm{ppm})$ and the existence of characteristic peak of $-\mathrm{CH} 2-\mathrm{CH} 2$ ( $\left.\delta 3.6 \mathrm{ppm}\right)$ 
indicates the intercepted part of the broken PPPB is PCA-PEG1000, which means that $\mathrm{pH} /$ redox stimulus responsiveness have occurred.

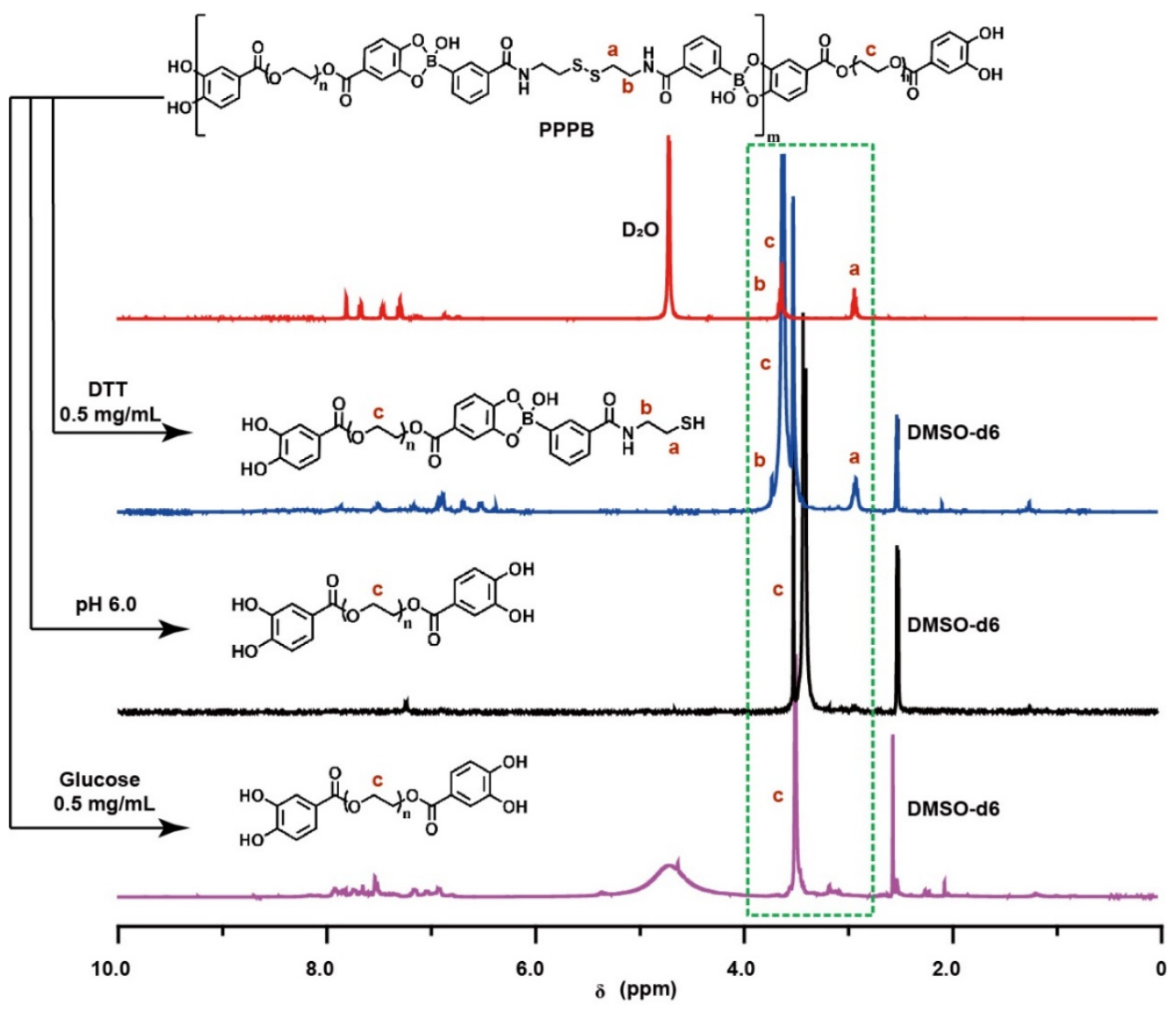

Figure 3. ${ }^{1} \mathrm{H}-\mathrm{NMR}$ spectrums of PPPB in PBS buffer ( $\mathrm{pH}$ 6.0), glucose aqueous solution $(0.5 \mathrm{mg} / \mathrm{mL})$ and DTT aqueous solution $(0.5 \mathrm{mg} / \mathrm{mL})$.

\subsection{Construction of the of (MMT-PPPB-CHA $)_{n}$ Coating}

Based on multi-stimulus responsive polymer PPPB, we designed a layer-by-layer assembly coating with the specificity of the response to the bacterial infection microenvironment (weak acid environment $(\mathrm{pH}<5)$, high peptidoglycan content, and high glutathione content) (Figure 1). We chose cellulose acetate membrane (CA), polyacrylonitrile membrane (PAN), polyvinyl chloride membrane (PVC), and polyurethane membrane (PU) as substrates to prepare the coating (MMT-PPPB-CHA) 3 because they are common medical materials in the clinic [31]. According to the color change of the substrate surface, it is preliminarily concluded that (MMT-PPPPB-CHA) 3 coating could be prepared on various substrate materials. As shown in Figure S4, the surfaces of coated groups appeared even rougher than uncoated groups. Moreover, the change of water contact angle can prove that the coating can obviously improve the hydrophilicity of the substrate, which is helpful to improve the affinity of medical devices to human body (Figure S5). According to the cross-section of the coating (Figure $4 \mathrm{a}-\mathrm{c}$ ), (MMT-PPPB-CHA) 3 coating could present a thick and loose layer stacking state. The reasons could be explained by zeta potential (Figure $4 \mathrm{~d}$ ). After the coatings have been successfully prepared on the substrate, they are gently scraped off and configured to a $0.5 \mathrm{mg} / \mathrm{mL}$ suspension (the solvent is pure water). Zeta potential of the sample was measured by Malvern Mastersizer 2000. Both MMT and PPPB exhibit electronegativity, which was very favorable for loading the positively charged $\mathrm{CHA}$ with electrostatic interaction. In addition, (MMT-CHA $)_{3}$ exhibited a weak positive charge after LbL self-assembly of MMT and CHA, which also proved the possibility of PPPB participating in electrostatic interaction. Finally, (MMT-PPPB-CHA) 3 coatings were 
negatively charged, confirming the electrostatic interaction between MMT, PPPB, and CHA. This interaction could be beneficial for CHA loading and enlarge the layer spacing of the coating. It can be seen from Figure $3 e$ that the $(001)$ diffraction peak of $(\mathrm{MMT})_{3}$ and (MMT-CHA $)_{3}$ are very obvious, which are corresponded to an interlayer d spacing of $1.2357 \mathrm{~nm}$ and $1.3043 \mathrm{~nm}$ respectively, according to Bragg's equation. The (001) interlayer spacing of $(\mathrm{MMT})_{\mathrm{n}}$ increased about $0.0686 \mathrm{~nm}$ after co-deposition with $\mathrm{CHA}$, indicating that some of CHA was loaded between MMT layers by ion exchange [25,32]. However, the (001) diffraction peak of (MMT-PPPB-CHA) $)_{3}$ can not be observed, indicating that the addition of PPPB completely destroyed the layered ordering structure of MMT. Finally, FT-IR absorbance spectrum demonstrated that (MMT-PPPB-CHA)3 coating was prepared successfully (Figure 4f).

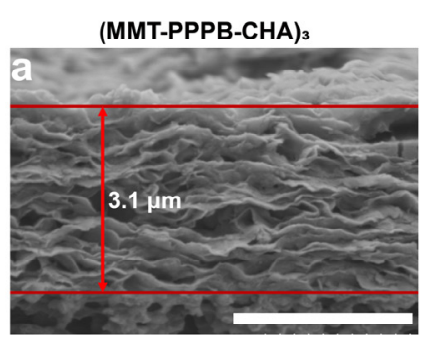

d

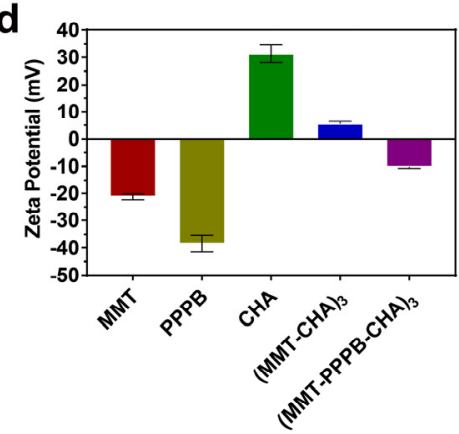

$(\text { MMT-CHA })_{3}$
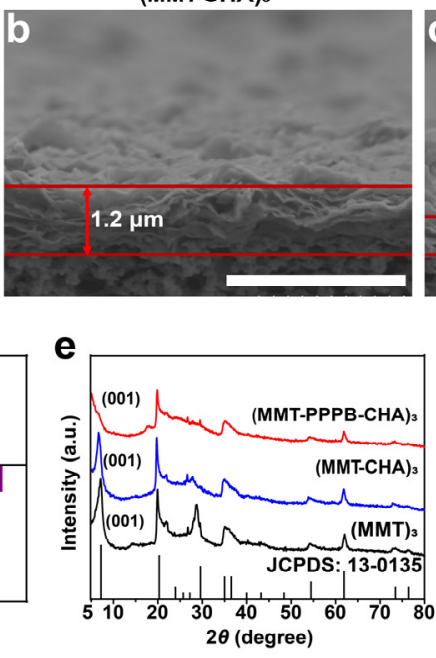

(MMT)
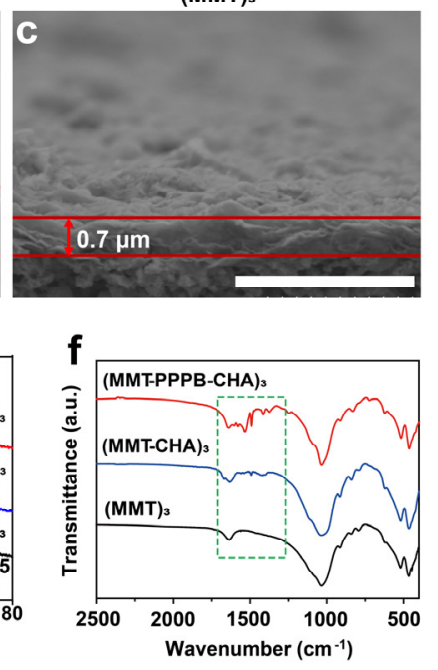

Figure 4. The SEM micrograph of cross-sectional of (a) MMT-PPPB-CHA $)_{3},(\mathbf{b})(\mathrm{MMT}-\mathrm{CHA})_{3}$, and (c) $(\mathrm{MMT})_{3}$ coating. Scale bar: $3 \mu \mathrm{m}$; (d) Zeta potential of MMT, PPPB, CHA, (MMT-CHA) ${ }_{3}$ and (MMT-PPPB-CHA $)_{3}$; (e) XRD patterns and (f) FT-IR absorbance spectrums of $(\mathrm{MMT})_{3},(\mathrm{MMT}-\mathrm{CHA})_{3}$, (MMT-PPPB-CHA) $)_{3}$.

\subsection{CHA Loading Capacity and Releasing Kinetics of (MMT-PPPB-CHA $)_{n}$ Coating}

Herein, CHA loading capacity and kinetics of CHA releasing in (MMT-PPPB-CHA) coating were studied. As shown in Figure S6, the drug loading of (MMT-PPPB-CHA) coating had a linear relationship with the number of layers (n). This result was in line with our expectation that number of layers could regulate the CHA loading dosages in (MMTPPPB-CHA) n coating. According to Figure S7, the drug release rate of (MMT-PPPB-CHA) coating was less than $30 \%$, while the drug release rate of (MMT-CHA) n was more than $60 \%$ within $72 \mathrm{~h}$. This indicated that (MMT-PPPB-CHA) coating possessed good sustained release capacity.

\subsection{Multistimulus-Responsive Drug Release Behavior of (MMT-PPPB-CHA ${ }_{n}$ Coating}

The ability of sustained release alone does not play a role in inhibiting bacterial resistance. Prolonged exposure to drugs can encourage bacteria to develop drug resistance. Therefore, a controlled drug delivery system in response to bacterial infection microenvironment (weak acid environment $(\mathrm{pH}<5)$, high peptidoglycan content, and high glutathione content) is very important. Considering the presence of multi-stimulus responsive PPPB, (MMT-PPPB-CHA) ${ }_{3}$ coating should theoretically be capable of responsive drug release. Therefore, the multi-stimulus responsive drug release behavior of (MMT-PPPB-CHA) 3 coating was studied (Figure 5). As shown in Figure 5a, the release rate of CHA was only about 
$20 \%$ in the alkaline or neutral phase $(\mathrm{pH} 8.0-7.0)$. When $\mathrm{pH}$ reduced to 5.5 , the CHA release rate increased to $40 \%$ within $72 \mathrm{~h}$. The lower the $\mathrm{pH}$ value, the higher the CHA release rate. Moreover, according to Figure $5 b, c$, the $\mathrm{CHA}$ release rate increased with the increased glucose and DTT concentration. When glucose concentration was $1.0 \mathrm{mg} / \mathrm{mL}$, the CHA release rate can reach about $35 \%$ and $65 \%$ within $72 \mathrm{~h}$ respectively. This responsive drug release behavior of the (MMT-PPPB-CHA) ${ }_{3}$ coating was related to the dynamic boronate ester and disulfide bonds in the polymer PPPB. The dynamic covalent bonds in PPPB could be reversibly fractured in weak acid environment $(\mathrm{pH}<7.0)$, high peptidoglycan solution $(0.5 \mathrm{mg} / \mathrm{mL})$, and high glutathione solution $(0.5 \mathrm{mg} / \mathrm{mL})$. When bond fracture occurs in PPPB, the layered structure of (MMT-PPPB-CHA) 3 coating gradually became loose and the gradual release of the CHA was started.
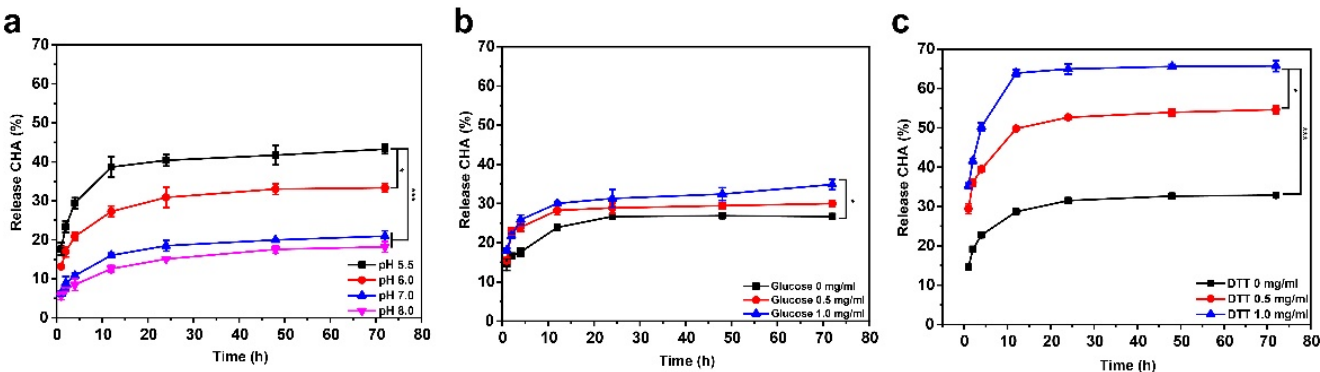

Figure 5. CHA release curves of (MMT-PPPB-CHA) 3 within $72 \mathrm{~h}$ in (a) different $\mathrm{pH}(5.5,6.0,7.0$ and 8.0$),(\mathbf{b})$ concentrations of glucose $(0,0.5,1.0 \mathrm{mg} / \mathrm{mL})$ and $(\mathbf{c})$ DTT $(0,0.5,1.0 \mathrm{mg} / \mathrm{mL})$ solutions. ${ }^{*} p<0.05,{ }^{* * *} p<0.001$.

The above results showed that (MMT-PPPB-CHA) ${ }_{3}$ coating exhibited responsive drug release ability in different $\mathrm{pH}(5.5,6.0,7.0$ and 8.0$)$, concentrations of glucose $(0,0.5$, $1.0 \mathrm{mg} / \mathrm{mL})$ and DTT $(0,0.5,1.0 \mathrm{mg} / \mathrm{mL})$ solutions, respectively. However, these factors exist together in a real infectious environment. Therefore, we studied the influence of these three factors $(\mathrm{pH}$, glucose, and DTT) on CHA release rate. Based on the investigation of single factors, the three factors, namely $\mathrm{pH}$ (factor A), glucose (factor B), and DTT (factor C) were selected. CHA release rate was regarded as investigating indicator for screening the optimal combination of three factors through the orthogonal test $\mathrm{L}_{9}\left(3^{4}\right)$ (three factors and three levels) as shown in Table 1 [33]. The average drug release rate was the highest in group $\mathrm{c}$ and the lowest in group $\mathrm{h}$, while the drug release levels of groups $\mathrm{a}, \mathrm{b}, \mathrm{d}$, e, and $\mathrm{f}$ were similar. It indicated that the optimal combination of factors to promote $\mathrm{CHA}$ release was pH 6.0, glucose $1.0 \mathrm{mg} / \mathrm{mL}$ and DTT $1.0 \mathrm{mg} / \mathrm{mL}$. However, the effects of the three factors on the drug release rate of the coating also have a certain order. To explore this order, we analyzed the extremum values (R) which indicates the importance degrees of three factors in Table [34]. By comparing the R-value, the significance order of the three factors on the average $\mathrm{CHA}$ release rate was $\mathrm{pH}>\mathrm{DTT}>$ glucose. Therefore, it can be concluded that $\mathrm{pH}$ had the greatest influence on the drug release of the coating.

\subsection{In Vitro Antibacterial Activity of (MMT-PPPB-CHA $)_{n}$ Coating}

Given the results of orthogonal test, we further studied the antibacterial properties of (MMT-PPPB-CHA) ${ }_{3}$ coating in vitro. As shown in Figure $6 \mathrm{a}, \mathrm{b}$, bacterial mortality rate of (MMT-PPPB-CHA) $)_{3}$ group reached about $99 \%$ in $4 \mathrm{~h}$ at a normal environment against $S$. aureus and E. coli. When coating degradation triggered by weak acid environment ( $\mathrm{pH} 6.0$ ), glucose solution $(1.0 \mathrm{mg} / \mathrm{mL})$, and DTT solution $(1.0 \mathrm{mg} / \mathrm{mL}),(\text { MMT-PPPB-CHA })_{3}$ coating could kill $99 \%$ of $S$. aureus and E. coli only in $2 \mathrm{~h}$. We speculated that the reason for this might be the high $\mathrm{CHA}$ releasing rate of the (MMT-PPPB-CHA $)_{3}$ coating. According to Figures S6 and S7, the minimum release amount of CHA was $23 \mu \mathrm{g}(n=3)$. This dose $(23 \mu \mathrm{g} / \mathrm{mL})$ was still above the MIC of CHA $(1.0 \mu \mathrm{g} / \mathrm{mL})$ according to the literature we reviewed [35]. This caused the bacteria to be killed more quickly in higher concentrations of CHA. 
a

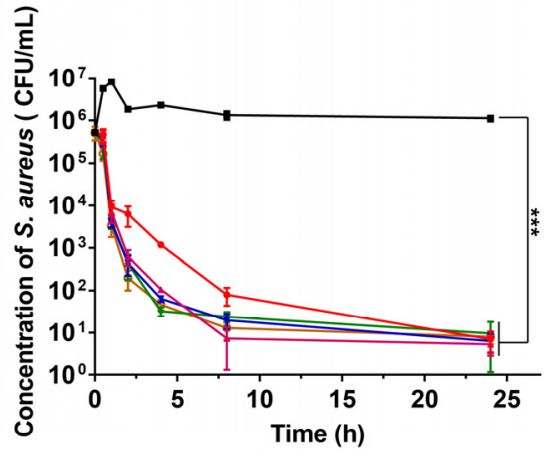

b

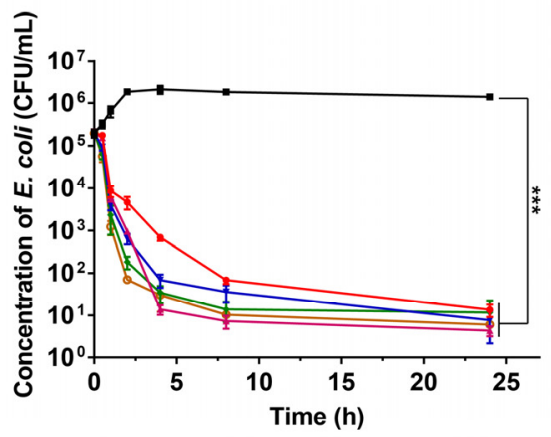

$\rightarrow$ No coating $\rightarrow$ Coating $\rightarrow$ Coating + glucose $1.0 \mathrm{mg} / \mathrm{mL} \rightarrow$ Coating $+\mathrm{pH} 6.0 \rightarrow$ Coating + DTT $1.0 \mathrm{mg} / \mathrm{mL}$

- Coating + Multistimulus (glucose $1.0 \mathrm{mg} / \mathrm{mL}+\mathrm{pH} 6.0+\mathrm{DTT} 1.0 \mathrm{mg} / \mathrm{mL}$ )

Figure 6. Stimulation-responsive killing effects of (MMT-PPPB-CHA) 3 on high concentrations of (a) S. aureus and (b) E. coli after incubating for 24 h. ${ }^{* * *} p<0.001$.

The efficient bactericidal ability can inhibit the development of bacterial resistance, but it does not mean that the medical device surface can be better protected. In particular, cationic antimicrobial modified surfaces are more likely to adsorb bacterial debris. If the dead bacteria can't be cleaned up quickly, they can provide an attachment site for other living bacteria. In this case, the antibacterial surface can quickly fail and the medical device becomes contaminated. Previous results have proved that the layered self-assembly (MMT-PPPB-CHA $)_{3}$ coating has strong electronegativity and hydrophilicity. According to the literature, these properties should endow the coating with good anti-adhesion capacity [18]. Herein, bacterial adhesion on (MMT-PPPB-CHA) ${ }_{3}$ coating was observed in PBS buffer ( $\mathrm{pH} 5.5,6.0,7.0$ and 8.0), glucose aqueous solution $(0.5$ and $1.0 \mathrm{mg} / \mathrm{mL})$ and DTT aqueous solution $(0.5$ and $1.0 \mathrm{mg} / \mathrm{mL})$. FITC labelled S. aureus $\left(2 \times 10^{6} \mathrm{CFU} / \mathrm{mL}\right)$ and E. coli $\left(2 \times 10^{6} \mathrm{CFU} / \mathrm{mL}\right)$ were co-cultured with the (MMT-PPPB-CHA $)_{3}$ coating. As shown in Figure 7a, Figures S8a and S9a, (MMT-PPPB-CHA) ${ }_{3}$ coating could effectively inhibit the growth of bacteria within $2 \mathrm{~h}$ in different solutions (PBS buffer ( $\mathrm{pH}$ 5.5, 6.0, 7.0 and 8.0$)$, glucose aqueous solution $(0.5$ and $1.0 \mathrm{mg} / \mathrm{mL}$ ) and DTT aqueous solution $(0.5$ and $1.0 \mathrm{mg} / \mathrm{mL}))$, respectively. The number of visible bacteria was significantly reduced ( $99 \%$ reduction) (Figures S10 and S11). Moreover, only a few bacteria fragments could be on the (MMT-PPPB-CHA) 3 coating (Figures $7 \mathrm{~b}, \mathrm{~S} 8 \mathrm{~b}$ and $\mathrm{S} 9 \mathrm{~b}$ ). By contrast, the bacteria survived well on the uncoated substrates (Figures 7c, S8c and S9c).

After proving the anti-adhesion property, we further explored the recyclability of the (MMT-PPPB-CHA $)_{3}$ coating. The substrate covered with different coatings was reused for six cycles ( $4 \mathrm{~h}$ as 1 cycle) (Figure 8 ). The concentration of the bacteria increased to $10^{8}-10^{9} \mathrm{CFU} / \mathrm{mL}$ after $4 \mathrm{~h}$ in the uncoated group. For CHA coating (Figure $8 \mathrm{~b}$ ), the complete killing of $S$. aureus and E. coli was achieved in the first cycle and lost its antibacterial properties in the following cycle. As shown in Figure 8c, the (MMT-CHA) 3 coating achieved effect bacterial killing in two cycles but began to lose its antibacterial ability in the third cycle. According to Figure 8d, (MMT-PPPB-CHA) ${ }_{3}$ coating completely killed S. aureus and E. coli in four cycles. In the fifth and sixth cycles, low concentrations $\left(10^{3} \mathrm{CFU} / \mathrm{mL}\right)$ of $S$. aureus and E. coli appeared on the surface of the coating, respectively. It could be thus concluded that (MMT-PPPB-CHA) 3 coating can maintain a long-term antibacterial effect. 
a

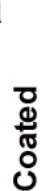

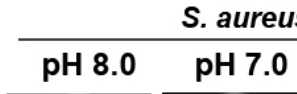

aureus

pH 6.0

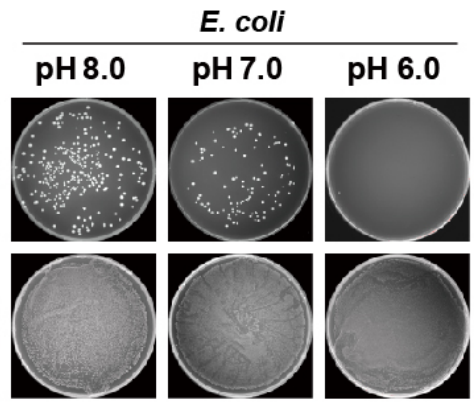

b
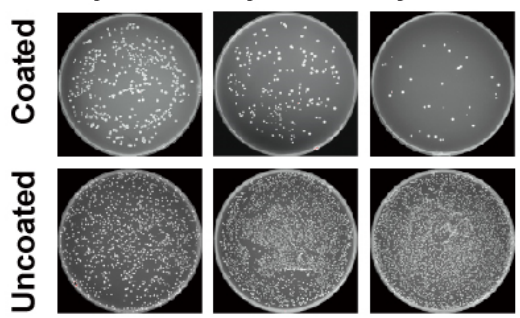

S. aureus
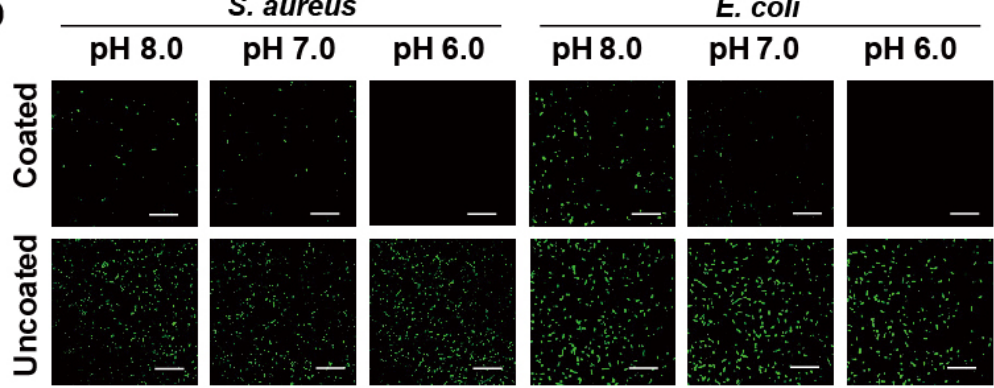

C
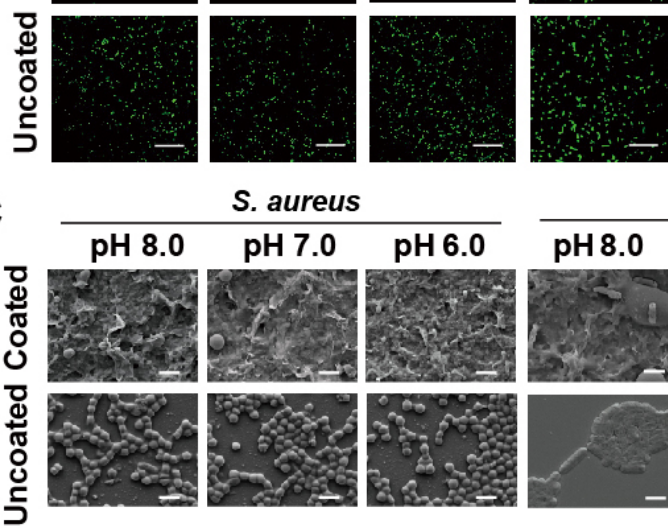

E. coli
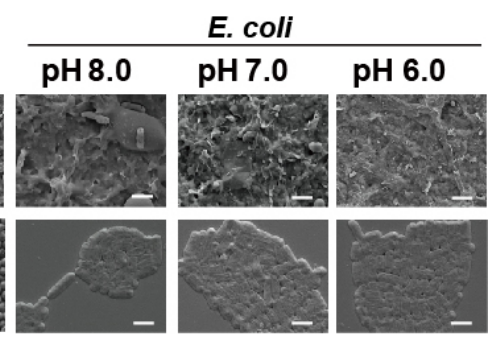

Figure 7. (a) Images of bacterial clones on the agar plates after treatment with (MMT-PPPB-CHA) 3 coating for $2 \mathrm{~h}$ under different $\mathrm{pH}$ values (6.0, 7.0, and 8.0); (b) CLSM diagrams and (c) SEM images of bacterial adhesion on the (MMT-PPPB-CHA) 3 coating at different $\mathrm{pH}$ values $(6.0,7.0$ and 8.0) for $2 \mathrm{~h}$. Scale bar: $20 \mu \mathrm{m}$ and $1 \mu \mathrm{m}$.
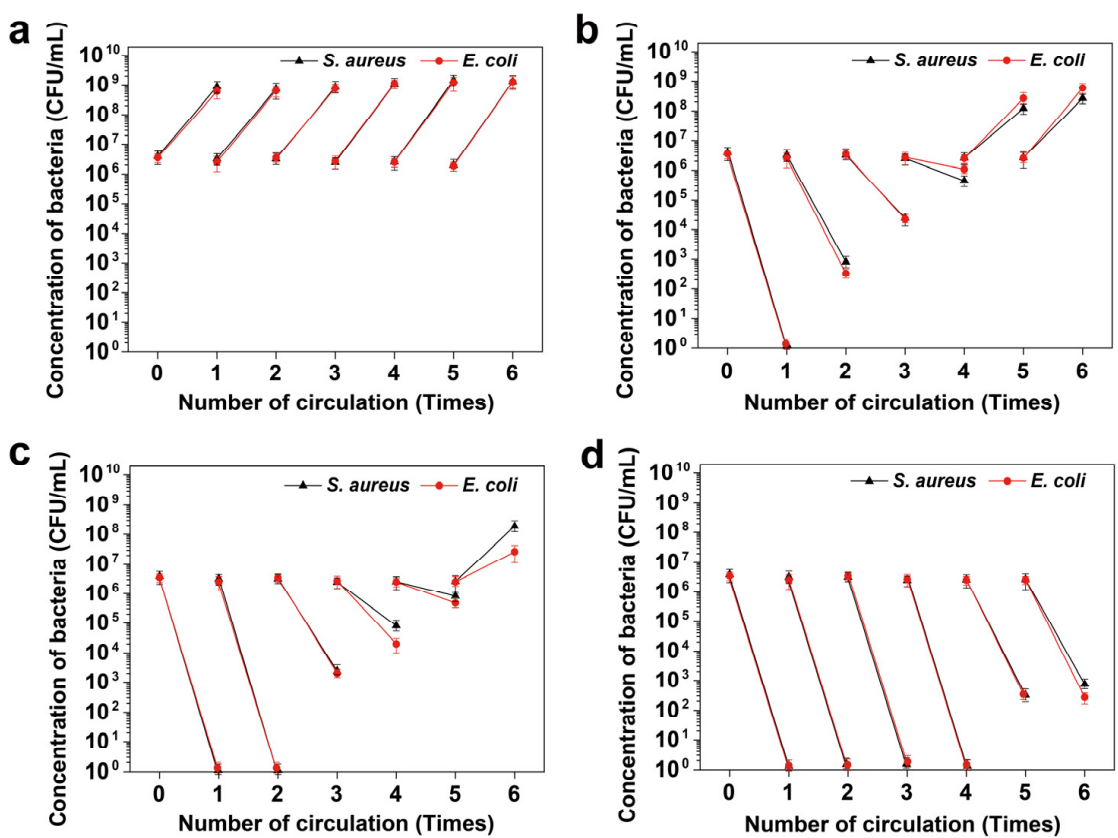

Figure 8. Bacteria cyclic killing effects of (a) Uncoated, (b) CHA coated, (c) (MMT-CHA) 3 coated and (d) (MMT-PPPB-CHA) ${ }_{3}$ coated substrate against $S$. aureus and E. coli. 


\subsection{In Vivo Antibacterial Activity and Full-Thickness Skin Defect Healing of (MMT-PPPB $\mathrm{CHA})_{n}$ Coating}

Given the highly effective antibacterial efficacy of (MMT-PPPB-CHA) ${ }_{3}$ coating in vitro, we studied its in vivo antibacterial performance in an infected mouse model. The process of animal experimentation was depicted in Figure 9a. We inoculated the back of the mouse with bacteria, and cut it open with a scalpel to form an open resection of the infected wound where there were obvious signs of suppurative infection. Then, different coatings were used for treatment. The wound healing of the subcutaneous infected site in mice was observed and photographed on days 1, 5, 10, and 14, respectively, as shown in Figure 9b. The wounds treated with CHA, (MMT-CHA) ${ }_{3}$ and (MMT-PPPB-CHA) $)_{3}$ coatings showed no further deterioration and a good healing trend. As shown in Figure 9c,d, (MMT-PPPB-CHA) 3 coating treated wounds healed $91-97 \%$ after 14 days, respectively. However, the infected wounds in the untreated group and the blank substrate group were basically in a state of severe infection. Some symptoms of suppurative infection still existed after 14 days. The healing rates of S. aureus and E. coli infected wounds were $63 \%$ and $72 \%$, respectively. After 14 days, the tissues of the infected site were fully soaked in sterile normal saline and inoculated on AGAR plates to observe the bacteria colony growth, as shown in Figure S11. It was observed that there were still many bacteria living in the infected sites of mice in the untreated group and blank group, indicating the infection did not been eliminated. By contrast, the wound tissue treated with CHA, (MMT-CHA) ${ }_{3}$ and (MMT-PPPB-CHA)n coatings was free of any bacteria.

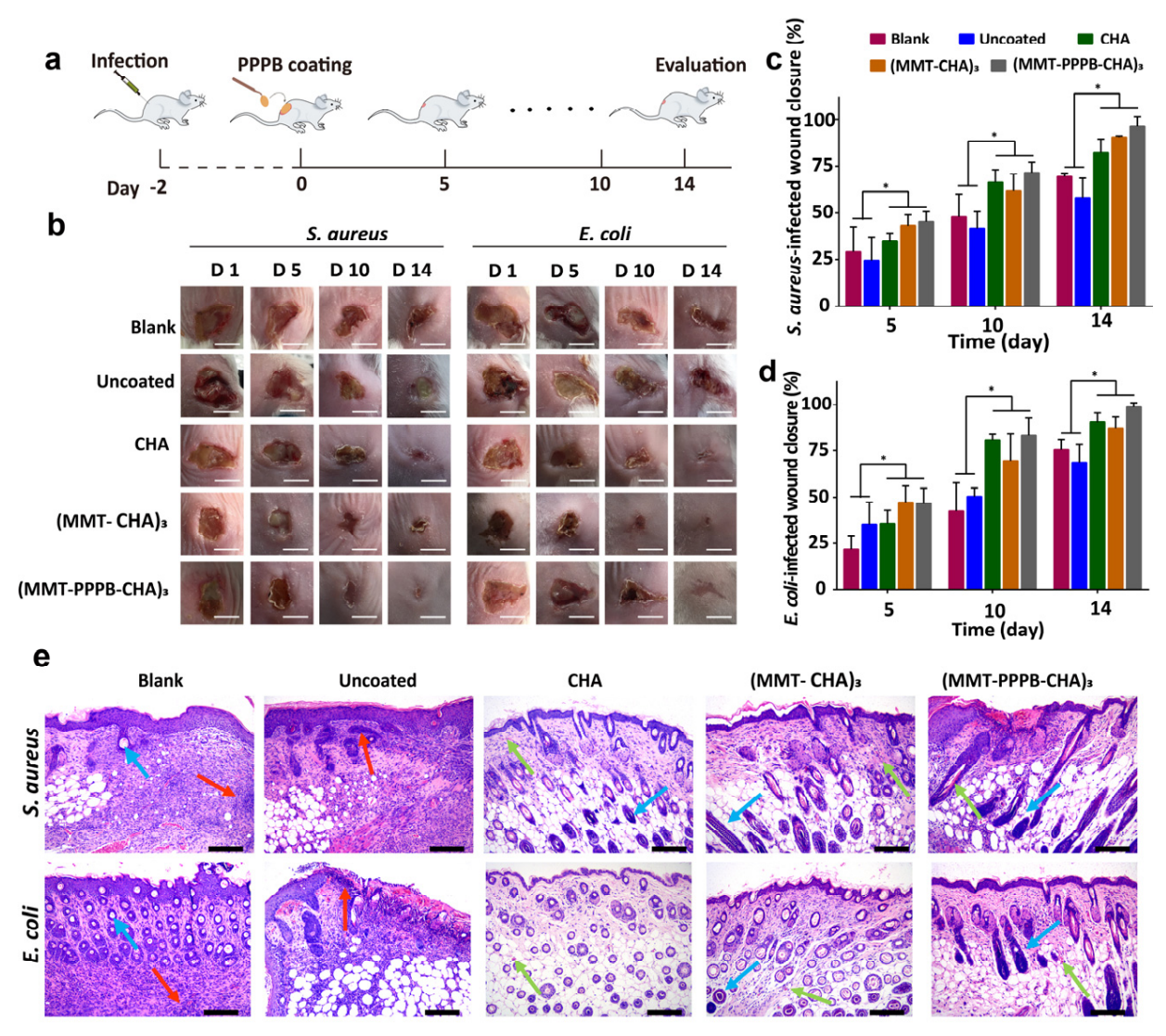

Figure 9. (a) Scheme of test of antibacterial activity and full-thickness skin defect healing in vivo; (b) Digital photographs of infected wound healing in vivo at days 1, 5, 10, and 14 after different treatments. Scale bar: $1 \mathrm{~mm}$; (c) S. aureus and (d) E. coli infected wound closure rates during the 14 days in treatment; (e) H \& E-staining results of healed skin tissues at determined times (blood vessels: green arrows, hair follicles: blue arrows, neutrophils: red arrows). Scale bar: $100 \mu \mathrm{m} .{ }^{*} p<0.05$. 
In clinical practice, medical instruments (e.g., peripherally inserted central catheter and urethral catheter) are exposed to wounds on the surface of the body for a long time [36]. During this time, bacteria have a chance to contaminate medical equipment and invade the body to cause infection [36]. Therefore, it is very important for the coating of medical devices to have high antibacterial properties and promote wound healing. Wound healing is a complex and orderly process consisting of four stages: hemostasis, inflammation, proliferation, and wound remodeling. Herein, $\mathrm{H} \& \mathrm{E}$ staining was applied to study the process of wound healing from a histological perspective (Figure 9e). The skin tissues in the untreated group and the blank substrate group exhibited acute inflammatory responses and displayed very little sprouting angiogenesis on the 14 days [37]. The results showed that the wound healing was in a transitional stage between inflammation and regeneration, indicating the infections in the wound were not resolved. Differently, the skin tissues treated (MMT-PPPB-CHA) ${ }_{3}$ coatings had regenerated hair follicles and capillaries. It is worth noting that the tissue treated with (MMT-PPPB-CHA) 3 coating showed better hair follicle regeneration, while $\mathrm{CHA}$ and (MMT-CHA)n group showed more angiogenesis. Considering the wound can regenerate a large number of blood vessels during the regeneration stage, and complete the degeneration of some blood vessels and generate hair follicles during the remodeling stage. The presence of more hair follicles indicated the best wound recovery in (MMT-PPPB-CHA) 3 group. In conclusion, a comparison of wound healing of each group showed that (MMT-PPPB-CHA $)_{3}$ coating group healed best no matter S. aureus or E. coli infected wounds, indicating that (MMT-PPPB-CHA)n coating had good biocompatibility (Figure S12). Moreover, it had the best bactericidal effect on the subcutaneous infected site, thus accelerating the elimination of infection and promoting wound repair.

\section{Conclusions}

In this study, a multi-stimulus responsive multilayer coating with controlled release of $\mathrm{CHA}$ was constructed for the treatment of DAIs. The in vitro studies highlighted the $\mathrm{pH}-$, glucose- and DTT-responsive abilities of (MMT-PPPB-CHA) $\mathrm{n}$ coating, and its antibacterial capacity. In medium with $\mathrm{pH} 6.0$, glucose $1.0 \mathrm{mg} / \mathrm{mL}$ and DTT $1.0 \mathrm{mg} / \mathrm{mL}$, the coating showed extremely high bactericidal ability ( $99 \%$ reduction). In real clinical scenario, the coating is intended to address bacterial infections that occur when medical devices (such as urinary catheters or peripheral venous catheters) are connected to open wounds in humans. The three components involved in the coating are biocompatible components. In vivo studies also show that the coating can kill bacteria quickly and promote wound healing within 14 days, which supports the coating as a non-toxic and highly bactericidal material. In addition, (MMT-PPPB-CHA) n coating could be reused 6 times with antibacterial ability, reducing the pain caused by frequent dressing changes for patients. However, it needs further research that whether the coating still has good antibacterial and biocompatibility in case applied for the stents and prosthetic devices in vivo.

Supplementary Materials: The following supporting information can be downloaded at: https:/ / www.mdpi.com/article/10.3390/jfb13010024/s1. Chemical structural formula, ${ }^{1} \mathrm{H}-\mathrm{NMR}$ spectrums, and FT-IR absorbance spectrums of BPBAC (Figure S1) and PCA-PEG1000 (Figure S2), the responsive mechanism of PPPB (Figure S3a), UV absorption spectrums of PPPB in different solutions (Figure S3b), SEM images (Figure S4) and water contact angles (Figure S5) of the surfaces of CA, PAN, PVC and PU substrates coated and uncoated with (MMT-PPPB-CHA)n,, the relationship between drug loading and the number the (MMT-PPPB-CHA)n bilayers (Figure S6), CHA release curves of (MMT-CHA)n and (MMT-PPPB-CHA)n coating (Figure S7), S. aureus and E. coli after treatment with (MMT-PPPBCHA)n coating for $2 \mathrm{~h}$ (Figures S8 and S9), concentrations of S. aureus and E. coli after incubating with (MMT-PPPB-CHA)n coating (Figures S10 and S11), the growth of S. aureus and E. coli in infected wound tissues after 14 days of different treatments (Figure S12). 


\begin{abstract}
Author Contributions: Conceptualization, W.L., G.H. and L.R.; methodology, W.L., G.H. and J.C.; investigation, Y.Z., X.Z. and X.W.; resources, L.R.; data curation, W.L. and G.H.; writing-original draft preparation, W.L.; writing-review and editing, W.L., M.W., B.F. and L.R.; visualization, L.R.; supervision, L.R.; project administration, L.R.; funding acquisition, L.R. All authors have read and agreed to the published version of the manuscript.
\end{abstract}

Funding: This work was supported by the National Natural Science Foundation of China (Grant No. 31870994 and U1904206) and Fujian Provincial Science and Technology Cooperation Project (20210002).

Institutional Review Board Statement: The animal study protocol was approved by the Ethics Committee of the Institutional Animal Care and Use Committee of Xiamen University (protocol code: XMULAC20180003 and date of approval: 26 February 2018).

Informed Consent Statement: The study did not involve humans.

Conflicts of Interest: The authors declare no conflict of interest.

\title{
References
}

1. Brooks, B.; Olm, M.R.; Firek, B.A.; Baker, R.; Geller-McGrath, D.; Reimer, S.R.; Soenjoyo, K.R.; Yip, J.S.; Dahan, D.; Thomas, B.C.; et al. The developing premature infant gut microbiome is a major factor shaping the microbiome of neonatal intensive care unit rooms. Microbiome 2018, 6, 12. [CrossRef] [PubMed]

2. Burny, F.; Donkerwolcke, M.; Moulart, F.; Bourgois, R.; Puers, R.; Van Schuylenbergh, K.; Barbosa, M.; Paiva, O.; Rodes, F.; Begueret, J.B.; et al. Concept, design and fabrication of smart orthopedic implants. Med. Eng. Phys. 2000, 22, 469-479. [CrossRef]

3. Arciola, C.R.; Campoccia, D.; Montanaro, L. Implant infections: Adhesion, biofilm formation and immune evasion. Nat. Rev. Microbiol. 2018, 16, 397-409. [CrossRef] [PubMed]

4. Weiner-Lastinger, L.M.; Abner, S.; Edwards, J.R.; Kallen, A.J.; Karlsson, M.; Magill, S.S.; Pollock, D.; See, I.; Soe, M.M.; Walters, M.S.; et al. Antimicrobial-resistant pathogens associated with adult healthcare-associated infections: Summary of data reported to the National Healthcare Safety Network, 2015-2017. Infect. Control. Hosp. Epidemiol. 2020, 41, 1-18. [CrossRef]

5. Zhou, C.; Wu, Y.; Thappeta, K.R.V.; Subramanian, J.T.L.; Pranantyo, D.; Kang, E.T.; Duan, H.W.; Kline, K.; Chan-Park, M.B. In Vivo Anti-Biofilm and Anti-Bacterial Non-Leachable Coating Thermally Polymerized on Cylindrical Catheter. ACS Appl. Mater. Interfaces 2017, 9, 36269-36280. [CrossRef]

6. Wang, B.L.; Liu, H.H.; Wang, Z.F.; Shi, S.; Nan, K.H.; Xu, Q.W.; Ye, Z.; Chen, H. A self-defensive antibacterial coating acting through the bacteria-triggered release of a hydrophobic antibiotic from layer-by-layer films. J. Mat. Chem. B 2017, 5, 1498-1506. [CrossRef]

7. Wei, T.; Yu, Q.; Chen, H. Responsive and Synergistic Antibacterial Coatings: Fighting against Bacteria in a Smart and Effective Way. Adv. Healthc. Mater. 2019, 8, 1801381. [CrossRef]

8. Chen, R.; Shi, C.; Xi, Y.; Zhao, P.; He, H. Fabrication of cationic polymer surface through plasma polymerization and layer-by-layer assembly. Mater. Manuf. Processes 2020, 35, 221-229. [CrossRef]

9. Liu, P.; Fu, K.; Zeng, X.; Chen, N.; Wen, X. Fabrication and Characterization of Composite Meshes Loaded with Antimicrobial Peptides. ACS Appl. Mater. Interfaces 2019, 11, 24609-24617. [CrossRef]

10. Liu, Z.; Ma, S.; Duan, S.; Deng, X.; Sun, Y.; Zhang, X.; Xu, X.; Guan, B.; Wang, C.; Hu, M.; et al. Modification of Titanium Substrates with Chimeric Peptides Comprising Antimicrobial and Titanium-Binding Motifs Connected by Linkers To Inhibit Biofilm Formation. ACS Appl. Mater. Interfaces 2016, 8, 5124-5136. [CrossRef]

11. Bhaskara, U.R.; Warmoeskerken, M.; Nabers, M.G.D.; Nanomi, B.V. Antimicrobial Functionalization of beta-Cyclodextrin Treated Fabrics. AATCC J. Res. 2016, 3, 15-24. [CrossRef]

12. Zhou, C.; Wang, F.; Chen, H.; Li, M.; Qiao, F.; Liu, Z.; Hou, Y.; Wu, C.; Fan, Y.; Liu, L.; et al. Selective Antimicrobial Activities and Action Mechanism of Micelles Self-Assembled by Cationic Oligomeric Surfactants. ACS Appl. Mater. Interfaces 2016, 8, $4242-4249$. [CrossRef]

13. Yao, Q.Q.; Ye, Z.; Sun, L.; Jin, Y.Y.; Xu, Q.W.; Yang, M.; Wang, Y.; Zhou, Y.L.; Ji, J.; Chen, H.; et al. Bacterial infection microenvironment-responsive enzymatically degradable multilayer films for multifunctional antibacterial properties. J. Mat. Chem. B 2017, 5, 8532-8541. [CrossRef]

14. Saha, K.; Butola, B.S.; Joshi, M. Synthesis and characterization of chlorhexidine acetate drug-montmorillonite intercalates for antibacterial applications. Appl. Clay Sci. 2014, 101, 477-483. [CrossRef]

15. Datta, S.M. Clay-polymer nanocomposites as a novel drug carrier: Synthesis, characterization and controlled release study of Propranolol Hydrochloride. Appl. Clay Sci. 2013, 80-81, 85-92. [CrossRef]

16. Fillion, M.; Goudreault, M.; Voyer, N.; Bechinger, B.; Auger, M. Amphiphilicity Is a Key Determinant in the Membrane Interactions of Synthetic 14-mer Cationic Peptide Analogues. Biochemistry 2016, 55, 6919-6930. [CrossRef]

17. Chen, H.; Jin, Y.Y.; Wang, J.J.; Wang, Y.Q.; Jiang, W.Y.; Dai, H.D.; Pang, S.Y.; Lei, L.; Ji, J.; Wang, B.L. Design of smart targeted and responsive drug delivery systems with enhanced antibacterial properties. Nanoscale 2018, 10, 20946-20962. [CrossRef] 
18. Li, M.; Wang, H.Q.; Chen, X.M.; Jin, S.N.; Chen, W.; Meng, Y.C.; Liu, Y.; Guo, Y.S.; Jiang, W.Y.; Xu, X.; et al. Chemical grafting of antibiotics into multilayer films through Schiff base reaction for self-defensive response to bacterial infections. Chem. Eng. J. 2020, 382, 122973. [CrossRef]

19. Xu, Q.W.; Li, X.; Jin, Y.Y.; Sun, L.; Ding, X.X.; Liang, L.; Wang, L.; Nan, K.H.; Ji, J.; Chen, H.; et al. Bacterial self-defense antibiotics release from organic-inorganic hybrid multilayer films for long-term anti-adhesion and biofilm inhibition properties. Nanoscale 2017, 9, 19245-19254. [CrossRef]

20. Zhao, Y.Q.; Sun, Y.J.; Zhang, Y.D.; Ding, X.K.; Zhao, N.N.; Yu, B.R.; Zhao, H.; Duan, S.; Xu, F.J. Well-Defined Gold Nanorod/Polymer Hybrid Coating with Inherent Antifouling and Photothermal Bactericidal Properties for Treating an Infected Hernia. ACS Nano 2020, 14, 2265-2275. [CrossRef]

21. Wei, T.; Zhan, W.J.; Yu, Q.; Chen, H. Smart Biointerface with Photoswitched Functions between Bactericidal Activity and Bacteria-Releasing Ability. ACS Appl. Mater. Interfaces 2017, 9, 25767-25774. [CrossRef] [PubMed]

22. Nastyshyn, S.; Raczkowska, J.; Stetsyshyn, Y.; Orzechowska, B.; Bernasik, A.; Shymborska, Y.; Brzychczy-Wloch, M.; Gosiewski, T.; Lishchynskyi, O.; Ohar, H.; et al. Non-cytotoxic, temperature-responsive and antibacterial POEGMA based nanocomposite coatings with silver nanoparticles. RSC Adv. 2020, 10, 10155-10166. [CrossRef]

23. Zhou, Y.; Zheng, Y.J.; Wei, T.; Qu, Y.C.; Wang, Y.R.; Zhan, W.J.; Zhang, Y.X.; Pan, G.Q.; Li, D.; Yu, Q.; et al. Multistimulus Responsive Biointerfaces with Switchable Bioadhesion and Surface Functions. ACS Appl. Mater. Interfaces 2020, 12, $5447-5455$. [CrossRef] [PubMed]

24. Chouirfa, H.; Bouloussa, H.; Migonney, V.; Falentin-Daudre, C. Review of titanium surface modification techniques and coatings for antibacterial applications. Acta Biomater. 2019, 83, 37-54. [CrossRef]

25. Wang, B.L.; Jin, T.W.; Xu, Q.W.; Liu, H.H.; Ye, Z.; Chen, H. Direct Loading and Tunable Release of Antibiotics from Polyelectrolyte Multilayers To Reduce Bacterial Adhesion and Biofilm Formation. Bioconjugate Chem. 2016, 27, 1305-1313. [CrossRef]

26. Manyi-Loh, C.; Mamphweli, S.; Meyer, E.; Okoh, A. Antibiotic Use in Agriculture and Its Consequential Resistance in Environmental Sources: Potential Public Health Implications. Molecules 2018, 23, 795. [CrossRef]

27. Iler, R.K. Multilayers of colloidal particles. J. Colloid Interface Sci. 1966, 21, 569-594. [CrossRef]

28. Richardson, J.J.; Cui, J.W.; Bjornmalm, M.; Braunger, J.A.; Ejima, H.; Caruso, F. Innovation in Layer-by-Layer Assembly. Chem. Rev. 2016, 116, 14828-14867. [CrossRef]

29. Zhang, X.H.; Ou-yang, S.; Wang, J.L.; Liao, L.; Wu, R.F.; Wei, J.C. Construction of Antibacterial Surface Via Layer-by-Layer Method. Curr. Pharm. Des. 2018, 24, 926-935. [CrossRef]

30. Singh, A.V.; Baylan, S.; Park, B.W.; Richter, G.; Sitti, M. Hydrophobic pinning with copper nanowhiskers leads to bactericidal properties. PLOS ONE 2017, 12, e0175428. [CrossRef]

31. Yu, H.-C.; Kim, Y.-K. Fractures of implant fixtures: A retroscccpective clinical study. Maxillofac. Plast. Reconstr. Surg. 2020, 42, 13. [CrossRef]

32. Lobato-Aguilar, H.; Uribe-Calderon, J.A.; Herrera-Kao, W.; Duarte-Aranda, S.; Baas-Lopez, J.M.; Escobar-Morales, B.; CauichRodriguez, J.V.; Cervantes-Uc, J.M. Synthesis, characterization and chlorhexidine release from either montmorillonite or palygorskite modified organoclays for antibacterial applications. J. Drug Deliv. Sci. Technol. 2018, 46, 452-460. [CrossRef]

33. Song, X.P.; Tang, J. Extraction Optimization, Preliminary Characterization and Bioactivities in Vitro of Ligularia hodgsonii Polysaccharides. Int. J. Mol. Sci. 2016, 17, 788. [CrossRef]

34. Wang, W.T.; Wu, B.; Qin, H.; Liu, P.T.; Qin, Y.; Duan, G.W.; Hu, G.Q.; He, M.X. Genome shuffling enhances stress tolerance of Zymomonas mobilis to two inhibitors. Biotechnol. Biofuels 2019, 12, 288. [CrossRef]

35. Fan, W.; Sun, Q.; Li, Y.Y.; Tay, F.R.; Fan, B. Synergistic mechanism of $\mathrm{Ag}^{+}-\mathrm{Zn}^{2+}$ in anti-bacterial activity against Enterococcus faecalis and its application against dentin infection. J. Nanobiotechnol. 2018, 16, 10. [CrossRef]

36. Li, W.T.; Zhang, H.X.; Li, X.L.; Yu, H.; Che, C.Y.; Luan, S.F.; Ren, Y.F.; Li, S.; Liu, P.; Yu, X.T.; et al. Multifunctional Antibacterial Materials Comprising Water Dispersible Random Copolymers Containing a Fluorinated Block and Their Application in Catheters ACS Appl. Mater. Interfaces 2020, 12, 7617-7630. [CrossRef]

37. Joshi, K.M.; Shelar, A.; Kasabe, U.; Nikam, L.K.; Pawar, R.A.; Sangshetti, J.; Kale, B.B.; Singh, A.V.; Patil, R.; Chaskar, M.G. Biofilm inhibition in Candida albicans with biogenic hierarchical zinc-oxide nanoparticles. Mater. Sci. Eng. C 2021, 112592. [CrossRef] 